\title{
“TANTO O FEMININO QUANTO O MASCULINO PRA MIM PARECE DE BOAS": PENSAR (RE)INVENÇÕES NO ENLACE ENTRE GÊNERO, IDENTIDADES E JUVENTUDES
}

\author{
Neilton dos Reis \\ Leandro Leal ${ }^{2}$ \\ Roney Polato de Castro ${ }^{3}$
}

Resumo: $\mathrm{O}$ artigo se propõe a pensar nas possibilidades de análise que se produzem quando se relaciona as categorias gênero, identidade e juventude. O cerne da escrita se organiza com as narrativas de jovens e suas experiências com a não-binaridade de gênero construídas a partir de uma pesquisa de mestrado em educação. Ao narrar experiências, esses sujeitos nos possibilitam (re)inventar modos de pensar as identidades, os sentidos de pertencimento e a materialidade que tais sentidos expressa em suas existências. As narrativas também nos dão pistas de como os sujeitos vão inventando estratégias de negociação e conflito com as normas, tomando como mote a questão do nome como expressão desse processo.

Palavras-chave: gênero; identidade; juventude; narrativa.

\section{"Both the feminine and the masculine seem to me to be good"? thinking (re) inventions in the link between gender, identities and youths}

\begin{abstract}
The article proposes to think about the possibilities of analysis that occur when we relate the categories gender, identity and youth. The core of writing is organized with the narratives of young people and their experiences with non-binarity of gender constructed from a masters research in education. In narrating experiences, these subjects enable us (re) to invent ways of thinking the identities, the senses of belonging and the materiality that these senses expresses in their existences. The narratives also give clues to how the subjects invent negotiation strategies and conflict with the norms, taking as motto the question of the name as an expression of this process. Keywords: gender; identity; youth; narrative.
\end{abstract}

\footnotetext{
'Universidade Federal de Minas Gerais. (neilton.dreis@gmail.com)

${ }^{2}$ Universidade Federal de São Carlos. (leandroleal@live.com)

${ }^{3}$ Universidade Federal de Juiz de Fora. (roneypolato@gmail.com)
}

$$
\begin{array}{lll}
\text { v. } 21 \text { n. } 47 \text { p. } 89-107 & \text { jul/set } 2019
\end{array}
$$




\section{INTRODUZINDO A DISCUSSÃO}

Experiências de jovens com a não-binaridade de gênero e suas estratégias de existência movem a escrita deste texto. Mais especificamente, queremos nos voltar para os processos de negociação com as normas, de capturas e resistências, envolvendo o enlace entre gênero, juventude e identidades. Assim, o objetivo deste texto é fazer uma discussão nesse enlace, partindo de narrativas que foram construídas com três jovens durante um processo de mestrado em Educação. Essas narrativas privilegiam um olhar para a invenção, a escolha e a utilização de estratégias por pessoas que tensionam o binário de gênero (ser homem ou ser mulher), sendo uma delas a questão do nome social.

Elfo, Irene e Netuno ${ }^{4}$ são as ${ }^{5}$ três jovens com as quais nos encontramos e conversamos durante a construção da pesquisa. Residentes em uma cidade do interior de Minas Gerais, elas se identificam com as experiências da nãobinaridade de gênero (uma categoria que tem se produzido em função da diferenciação do ser homem e do ser mulher). Em outras palavras, Elfo, Irene e Netuno ensejam romper com as identidades e expressões dos gêneros que se dizem exclusivamente masculinos ou exclusivamente femininos, rompendo também com a própria lógica binária do ou. No lugar, elas intentam borrar essas fronteiras dos gêneros e inventarem suas próprias formas de se desterritorializarem e (re)territorializarem nas relações, expressões e desejos.

Os encontros individuais com essas pessoas ocorreram duas ou três vezes entre os anos de 2016 e 2017. Nossas conversas giraram em torno de suas histórias de vida e foram gravadas em áudio, transcritas integralmente. Para este texto traremos duas narrativas (uma de Elfo e outra de Irene) e também uma crônica produzida em um dos encontros com Netuno e tudo que isso significou para a pesquisa.

Faremos uma pausa na apresentação para trata de uma importante dimensão para este texto e para as pesquisas que produzimos. A concepção de narrativa com a qual estamos trabalhando caminha na direção do que

\footnotetext{
${ }^{4}$ Elfo, Irene e Netuno são nomes fictícios escolhidos durante o processo da pesquisa. Mas, por que continuar a usar nomes fictícios se vou expor o nome social dessas pessoas? Continuo por duas razões. Primeiro porque priorizar apenas um nome em detrimento do outro (como veremos principalmente no caso de Netuno, mais a frente no texto) é um equívoco, uma vez que a pesquisa também produziu subjetivações e a escolha de um nome para participar dela faz parte disso. Em segundo, porque se isso gerar qualquer confusão é um ganho: ganhamos com a confusão, com o embaralhamento, com o "voltar para reler quem é quem”. Quem é quem?

${ }^{5}$ Nesse texto, "as" no feminino se refere a "pessoas", não a mulheres/meninas.
} 
argumenta Corinne Squire, ou seja, com uma visão ampla de "uma cadeia de signos com sentidos sociais, culturais e/ou históricos particulares" (2014, p. 273). Assim, o que procuramos é um caminhar junto a ao que nos contam os sujeitos. Não buscamos a interpretação das experiências ou alguma revelação do que está "por trás" de cada história narrada. Ao contrário, as utilizamos para operar com os conceitos (ou as palavras) produzidos durante cada conversa. Nesse sentido, vamos ao encontro de Cristina d'Ávila Reis quando pensamos que as "informações que são coletadas em um trabalho de campo não são dados passíveis de serem explicados, mas são significados produzidos no contexto pesquisado, que podem ser lidos e construídos de diferentes formas" (D'ÁVILA REIS, 2012, p. 247). Escolhemos voltar o olhar a partir das perspectivas pós-estruturalistas sobre essas construções narrativas e tencioná-las, fazê-las vibrar no campo do Gênero, da Sexualidade e da Educação.

As experiências narradas são acompanhadas da interpretação que fazemos delas, o que nos conduz a argumentar que não temos acesso a elas, mas apenas às suas sombras, a rápidas capturas. Da mesma forma, o próprio momento da conversa (e da pesquisa) se constituem como um disparador de experiências, de modo que este texto, as narrativas que ele visibiliza e constrói, desde sua produção, adquirem contornos de análises a partir de nossos olhares e nossas subjetividades. Nunca será, portanto, um real, algo da dimensão do verdadeiro, mas trata-se dos modos como vamos capturando os rastros desses registros narrativos e dando sentido a eles. É interessante pensar que as narrativas são produzidas a partir de uma relação. Toda palavra, todo conceito é emergente de um jogo. E é esse jogo que poderá ser o disparador da experiência, não apenas para as pessoas com quem conversamos, mas também para nós. Estamos territorializados com parcialidades, afetos, sentimentos. Cada narrativa sobre a qual nos demoramos produz efeito tanto para quem conta, quanto para quem ouve - podem provocar (des)subjetivações em todas as pessoas envolvidas nessa conversa.

Retomando os encaminhamentos da pesquisa, é importante sinalizar que os caminhos metodológicos foram trilhados seguindo os critérios de responsabilidade, cuidado e ética. Todas as pessoas assinaram um Termo de Consentimento, através do qual assumiram, de maneira voluntária, livre e esclarecida, os riscos e benefícios da pesquisa e se declaravam cientes dos objetivos e interesses da metodologia em questão. E, ainda, assinaram um termo adicional que permitia a exposição de seus nomes sociais, uma vez que, no meio do processo, entendemos a importância dessa dimensão em suas vidas. Assim, a pesquisa caminhou no sentido do respeito e da sensibilidade para com os sujeitos. 
Esse texto está dividido em cinco partes: a primeira, esta introdução; a segunda, em que lançamos olhar às questões específicas da transgressão ao binário de gênero; depois passamos à discussão de identidades; prosseguimos com o atravessamento de juventudes; e finalizamos com algumas considerações acerca do que levantamos no artigo. Narrativas poéticas e políticas de juventudes, narrativas poéticas e políticas de Elfo, Irene e Netuno, narrativas poéticas e políticas nossas. Todas se embaralham e se hibridizam e se confundem e transam para a invenção desta escrita.

\title{
“UMA PEDRA SUPOSTAMENTE NÃO TERIA GÊNERO”: GÊNERO PARA ALÉM DO BINÁRIO
}

\begin{abstract}
Então, meu nome é Cristal. Eu escolhi esse nome mais por causa de uma neutralidade que ele traz. Porque, na prática, "cristal” é uma pedra e uma pedra supostamente não teria gênero. Mas as pessoas acabam tendendo a me tratar pelo feminino pelo fato de talvez identificarem Cristal como um nome feminino. Mas eu não me sinto muito confortável com isso. Mas eu também não me importo muito, porque eu gosto tanto da neutralidade dos nomes, mas fica muito difícil na prática. Então, tanto o feminino quanto o masculino pra mim parece de boas. (Irene - Conversa 1)
\end{abstract}

Pensar gênero. Não pensar apenas em conforto e desconforto, mas também naquilo que não está enquadrado nesse binário. A neutralidade impossível. Impossível? Falta sistema. Mas, que possíveis podemos inventar se estamos em uma lógica ocidental binária (HERMANN, 2014)? O que pode o gênero que não quer se limitar nessa lógica?

Supostamente uma pedra não tem gênero. Supostamente um nome sempre tem gênero. Supostamente estamos nos locomovendo nas impossibilidades. Supostamente isso é uma escrita. Supostamente parece de boas. Tanto o feminino quanto o masculino para mim parece de boas, mas o exclusivamente feminino ou o exclusivamente masculino não me apetece. Ao apontarmos "o" feminino e "o" masculino, não estamos nos filiando a qualquer corrente de pensamento que os toma como homogeneidade e fixidez. Dizer de gênero é dizer de uma construção social que vem se (re)produzindo em torno de um binário. Judith Butler vai dizer que os investimentos em vários binários instituem uma "grade de inteligibilidade cultural por meio da qual os corpos, 
gêneros e desejos são naturalizados" (BUTLER, 2003, p. 23). A naturalização opera no sentido de conciliar sexo genital feminino e o ser mulher, bem como o sexo genital masculino e o ser homem. Na mesma lógica, essas duas possibilidades se complementariam (e se confundiriam) com um desejo heterossexual.

Essa matriz heteronormativa de organização das relações de gênero será produzida e reproduzida em relações de poder. Inspirando-nos em Michel Foucault, entendemos que a norma não é um elemento natural (da mesma forma que não podemos entender o gênero ou o sexo nessa perspectiva). Ele nos diz: "a norma não é simplesmente um princípio, [...] é um elemento a partir do qual certo exercício do poder se acha fundado e legitimado" (FOUCAULT, 2002, p. 62). Os reforços de utilização de determinadas cores (azul para meninos, rosa para meninas), a escolha de nossos nomes, as regulações nos modos de ser e estar, os brinquedos que são dados às crianças e outras estratégias subjetivadoras, serão exercícios do poder que reiteram e fazem existir as normas de gênero. São técnicas para a instituição do exclusivamente feminino ou exclusivamente masculino, para conformação dos corpos - do modo de cortar o cabelo ao modo de ser e estar no mundo - para que se concretize a continuidade entre sexo, gênero e desejo. Portanto, a existência da norma depende de sua reafirmação, a partir de estratégias de poder sutis, refinadas, naturalizadas.

A partir dessa discussão, corroboramos Judith Butler (2014) quando ela aponta que entender o gênero como norma não é apenas dizer que se produzam verdades normalizadoras do que é ser homem e ser mulher, mas principalmente dizer que a norma está envolvida na construção das identidades dentro do que se projeta enquanto exclusivamente masculino e enquanto exclusivamente feminino. Irene nos diz desse processo, ao relatar que embora tenha tido a pretensão de escapar de certas normativas de gênero ao adotar o nome Cristal, as pessoas continuaram a situá-la a partir desse nome no lugar do exclusivamente feminino. Nas relações sociais de poder, as resistências ao binário de gênero vão sendo negociadas, vão produzindo sentidos plurais, num jogo de forças com as normas que legitimam o binário.

A escolha de um outro nome, a criação de possíveis, envolve também a dimensão legal dessas escolhas, algo que forçado o debate público a produzir sentidos outros a essa questão. A utilização de nome social por pessoas transgêneras é, para Berenice Bento (2014, p. 166), uma "criatividade inédita no cenário internacional”. Em outras palavras, no nosso país temos legislações inovadoras que versam sobre sua propriedade legal. Apesar do avanço nessa 
discussão que ganha o debate público, muitas resistências se produzem no jogo normativo dos gêneros. A mudança no nome de registro, acompanhada de outras estratégias micropolíticas de afirmação dos processos de identificação com as transgressões do binário de gênero, produzem experiências de abjeção, de controle dos corpos, de violências as mais diversas.

Ao investir nessa análise, sinalizamos que diferentes práticas normalizadoras virão para diferentes identidades: ter uma identidade masculina que tem ou teve uma vagina será sofrer sanções sociais diferentes e, por vezes, mais brutais que uma identidade masculina que teve um pênis desde sempre. Flertar com as possibilidades dos gêneros, negociar com o binário e tentar, como aponta Irene, uma neutralidade dessas identidades, pode produzir confusão e com ela tentativas de correção e normalização. Incorporando tal perspectiva podemos entender que

A questão acerca do que estará excluído da norma estabelece um paradoxo, pois se a norma confere inteligibilidade ao campo social e normatiza esse campo para nós, então estar fora da norma é continuar, em certo sentido, a ser definido em relação a ela. Não ser totalmente masculino ou não ser totalmente feminina é continuar sendo entendido exclusivamente em termos de uma relação a "totalmente masculino" e "totalmente feminina". (BUTLER 2014, p. 253).

Assim, ainda que abjetos, os sujeitos estão subjetivados em um entendimento binário. Diferenciar-se do binário é, ainda, tomá-lo como referência de linguagem para pensar a si e o mundo. É se utilizar do mesmo para dizer dessa diferenciação e, talvez, criar novas formas de identificação que se proponham expandir as existentes. Dizer que os sujeitos estejam à margem da norma ou fora dela é afirmar que estão imbricados na mesma, se referenciando por ela e também lhe servindo de parâmetros. É o que também indica Rita Laura Segato quando diz que os trânsitos, as circulações entre as posições, as fronteiras "passam a ser todas colonizadas pela lógica binária." (SEGATO, 2012, p. 125). Observamos como as nossas narrativas de experiências que intentam a não-binaridade ainda permanecem numa linguagem localizada dentro da estrutura binária. Observamos como isso nos possibilita apenas ter um olhar de sombra dos processos de diferenciação e identificação pelos quais passamos. Mesmo por meio desses discursos temos apenas algumas capturas dessas diferenças e identidades, vultos de nossas movimentações. 
Tensionar a matriz de normas nos movimenta no que era impensável. Mesmo sendo essa matriz a base para a construção do binário de gênero e da heteronormatividade, repleta de fortes investimentos, ela não é infalível: os sujeitos terão linhas de fuga - ainda que atravessadas pelas normas. Em outras palavras, ainda com Judith Butler, vemos que

\begin{abstract}
os espectros de descontinuidade e incoerência, eles próprios são concebíveis em relação a normas existentes de continuidade e coerência, são constantemente proibidos e produzidos pelas próprias leis que buscam estabelecer linhas causais ou expressivas de ligação entre o sexo biológico, o gênero culturalmente constituído e a "expressão" ou "efeito" de ambos na manifestação do desejo sexual por meio da prática sexual. (BUTLER, 2003, p. 38).
\end{abstract}

Ouvir Irene investir na estratégia de neutralidade que um nome pode trazer nos faz pensar em sujeitos que se deslocam nesses espectros de descontinuidade e incoerência, ainda que nas narrativas percebamos que a experiência não-binária é capturada a partir de relações com o binário de gênero, seus parâmetros e normas. As narrativas e percepções são dinâmicas, prosseguem e podem ganhar outras configurações para dizer dos parâmetros de compreender feminino e masculino e se compreender distante de um pertencimento a uma dessas categorias.

\title{
"TEM 2 ANOS QUE EU VENHO MUDANDO DE NOME": IDENTIDADES COMO EXPERIMENTAÇÃO E CONSTRUÇÃO
}

\footnotetext{
N.: E como nome você adota geralmente Ori agora?

Elfo: É, eu só uso Ori. Aí é bom que minha mãe não fica me perguntando tanta coisa também. Porque antes, os meninos me chamavam de Orion. Aí até eu não achava muito a minha cara, sabe. Orion faz lembrar uma pessoa tão máscula.

N.: Tem um quê de deus grego.

Elfo: Aí eu "ah, não tem nada a ver comigo". Aí eu tinha colocado Oscar. Porque juntando o meu nome todo dá Oscar. Porque é Oriene Salviano Carneiro. Aí eu usava o "O" do Oriene, o "s" do Salviano e o "car" do Carneiro. Aí eu "ah, sei lá. Esse Oscar também é meio estranho". Agora eu deixo só Ori, é mais bonitinho. Porque Ori não define nada, se é isso, se é aquilo. Ori está de bom tamanho.
} 
N.: Faz quanto tempo que você adotou Ori? E foi mudando... de Oscar pra Ori e tudo mais?

Elfo: Tem 2 anos que eu venho mudando de nome.

(Elfo - Conversa 1)

Teste. Experimentação. Invenção. Corte. Junção. Um nome que vai se construindo a partir daquilo que eu acho mais a minha cara. E o que é a minha cara? Qual cara eu possuo no hoje? Apenas uma cara? A movimentação de Elfo nos faz imaginar os processos de construção de qualquer cara, de qualquer característica, de qualquer representação, de qualquer identidade. E se "a identidade dos indivíduos é construída por meio do reconhecimento intersubjetivo, através do qual os sujeitos garantem a plena realização das suas capacidades e uma relação positiva consigo mesmos" (DAYRELL, 2014, p. 3), nos parece relevante pensar a questão dessa construção a partir dos parâmetros que Elfo nos traz na narrativa.

Importante mencionar que o conceito de identidade é plural e complexo. Há muitas pesquisas e diferentes perspectivas, enfoques e intenções quando se trabalha com essa dimensão da identidade em si. Stuart Hall indica: "como ocorre com muitos outros fenômenos sociais, é impossível oferecer afirmações conclusivas ou fazer julgamentos seguros sobre as alegações e proposições que estão sendo apresentadas" (HALL, 2011, p. 8-9). Assim, indicamos uma aproximação com perspectivas que incluem os estudos pósestruturalistas e culturais para problematizar os investimentos dos sujeitos na produção identitária, destacando o papel da cultura, do social, da linguagem nos processos de elaboração e significação de sentidos de pertencimento e posições de sujeito.

Como aponta Kathryn Woodward, "a construção da identidade é tanto simbólica quanto social” (2000, p. 10). A relação dessas duas dimensões trará conformações identitárias não apenas para os indivíduos, mas também para qualquer coisa que se engendre nas políticas de certa identidade - como a luta pelo nome social, por exemplo. Quando pensamos as questões de gênero, construir identidades será perpassar por esses fatores de ordem tanto material quanto subjetiva. Quando Elfo narra suas (in)definições de nome, destacando que vem mudando-o há dois anos, ele menciona a relação com os outros e como percebem sua existência a partir desse nome. Em outros momentos da narrativa, Elfo nos fala das materialidades constitutivas desse processo, envolvendo suas roupas, seu cabelo e outros elementos que seriam definidores de sua identidade. 
Para Leonardo Guimarães et al, o nome "está fortemente conectado a física onde abrange o direito do corpo, integridade moral compreendendo o direito da liberdade e a honra, enfim, o nome exerce toda a função da capacidade civil dos indivíduos" (GUIMARÃES et al, 2016, p. 67). Podemos compreender, nessa perspectiva, o cuidado com os nomes das participantes da pesquisa quando se percebem com experiências da não-binaridade dentro de uma preocupação identitária. E, ainda, esse como outro processo de afirmação da existência defendido por Judith Butler, e corroborado pelas observações de Karen Schwach (2012), quando indica que, mesmo não constando nos documentos de registro civil, há "uma enorme importância do nome na autoestima, representando um meio de inclusão social”.

Voltamos então a Kathryn Woodward (2010), em diálogo com Juarez Dayrell e Nilma Gomes (2004), para perceber que a construção da identidade é relacional:

a identidade é uma construção que cada um de nós vai fazendo por meio das relações que estabelece com o mundo e com os outros, a partir do grupo social a que pertence, do contexto familiar, das experiências individuais, de acordo com os valores, ideias e normas que organizam sua visão de mundo (DAYRELL; GOMES, 2004, p. 10).

Nesse sentido, colocar-se em processos de identificação e pertencimento de gênero e sexualidade e raça e classe e juventude (para citar alguns atravessamentos apenas), significa estar em relação a tantas outras caras, cortes e junções de outros indivíduos. Dar sentido a esses processos identitários implica negociar atravessamentos. Sentidos vão se produzindo quando jovens desestabilizam normas binárias de gênero, quando essas experiências se hibridizam. E a construção de um pertencimento identitário se dá especialmente a partir do encontro com os outros: seja quando nos diferenciamos daquilo que encaramos como totalmente feminino e totalmente masculino (por exemplo), seja quando nos aproximamos de experiências e que são próximas às nossas. Mas sem, no entanto, se colar em um pensamento que constrói mais e mais binários. A identidade, sendo relacional, não necessariamente irá pressupor binários. Há possibilidades de escape. Assim, a construção das identidades se daria tanto numa rejeição quanto numa ligação, borrando as limitações binárias no ou.

Vindo da narrativa de Elfo e indo ao encontro de Kathryn Woodward (2010), o esforço para a afirmação de certa identidade terá tanto causas quanto 
consequências na materialidade. As proposições, os modos de ser/estar/fazer, os argumentos e modificações na expressão identitária irão repercutir socialmente, causar desestabilizações, rejeições, aprovações, exclusões.

Todos esses atravessamentos podem ainda ser esgarçados quando nos debruçamos sobre as identidades. Outros questionamentos podem ser feitos: o que é preciso ter para algo se constituir como identidade? Apenas um pertencimento subjetivo (e não dizemos que isso é o que ocorre em todos os casos) é suficiente? As questões de gênero podem (devem?) ser entendidas como identidades culturais? Reconhecemos uma história, uma cultura, uma linguagem que diz desses processos? Que armadilhas e potencialidades estão imbricadas nessas perguntas?

Corroboramos a crítica de Maria Rita de Assis César (2014) quando diz que, dentro de um jogo de identidades, os "indivíduos e experiências inclassificáveis e ininteligíveis, de corpo e gênero, permanecem por definição excluídos do universo escolar e social mais amplo, ou nele são incluídos sob o preço de sua domesticação normalizada” (CÉSAR, 2014, p. 98-99). Nesse sentido, quando concerne às experiências da não-binaridade de gênero, por exemplo, - com suas características de multiplicidade e ininteligibilidade consideramos ser potente um mergulho na diferença. E também pela compreensão de que

As identidades são fabricadas por meio da marcação da diferença. Essa marcação da diferença ocorre tanto por meio de sistemas simbólicos de representação quanto por meio de formas de exclusão social. A identidade, pois, não é o oposto da diferença: a identidade depende da diferença. (WOODWARD, 2000, p. 3940, grifos da autora).

Reconhecemos a importância das políticas identitárias e reconhecemos, ao mesmo tempo, que elas apresentam limites quando se trata de tentar abarcar algumas experiências em uma representação eleita como símbolo da luta. Como indica Michel Foucault em uma entrevista: "sim, ela [a política de identidade sexuall é muito útil, mas é uma identidade que nos limita e, penso eu que temos (e devemos ter) o direito de ser livres" (FOUCAULT, 2004, p. 266). Assim, a diferença em si pode nos dar ferramentas outras para refletir sobre esses assuntos.

Tomamos posicionamento de Elfo, na invenção do seu nome como imaginação, para refletir a construção de identidades e diferenças nessa 
perspectiva foucaultiana de tensionar políticas identitárias, investindo em diferenciação, assumindo que ela traz limites em alguns momentos de vida.

Vale ressaltar, ainda, que não é possível esperar total coerência dos sujeitos - seja daqueles que conversam comigo, seja de nós mesmos. Somos sujeitos incoerentes. Somos sujeitos que vamos nos transformando com o tempo. Nesse sentido, aquela pessoa que não se vê em certa representação, poderá assumi-la em alguma dimensão em outros tempos (no nome social utilizado, na preocupação com o corpo, nos parâmetros para dizer do binário feminino/masculino); bem como aquela pessoa que preza por certa identidade poderá fomentar o questionamento se não estiver criando novas caixinhas, novas restrições à experiência. Mas, acreditando que identidade/diferença é um falso binário, pensamos que não é necessário que haja hierarquias nesses processos que são permeados por essas duas dimensões. Não é necessário valorar em outros binários (coerente/incoerente, bom/ruim, efetivo/ineficaz, necessário/descartável).

Tudo que se movimenta em um turvo labirinto de experimentações e experiências, entre cortes e junções. Um labirinto em que não se perdem apenas nós, mas nossas próprias caras e representações. Onde se perdem as definições, as limitações, as identidades e diferenças. A confusão: já passamos por aqui? $\mathrm{O}$ embaralhamento: não estaríamos voltando? $\mathrm{O}$ perder-se: não há saída. E queremos uma saída? Um fim? As construções das identidades são contínuas, celebrações móveis (para lembrar Hall, 2011), alucinação e desmoronamento, mudanças (para lembrar Elfo).

Durante todo esse movimentar-se em narrativas e gêneros e identidades e diferenças e labirintos, algo se fez presente: juventudes. Jovens escrevem, narram, se montam, inventam nomes. Mas, como o ser jovem atravessa essas dimensões?

\section{"MUITOS AFETOS E SABERES - CAMINHAM JUNTOS": JUVENTUDES SENDO ATRAVESSAMENTO}

A crônica: "O encontro com o despropósito"

Os bares e esquinas das ruas do bairro de São Pedro já foram temas de outros textos: os encantos que se passam, as emoções que se 
produzem, os amores que carregam, as poesias que inspiram. São também espaços dos encontros. Às margens da Universidade, a Cidade Alta respira movimentação, trânsito de madrugada a madrugada, risadas e companhia a todo momento. No outono, quando o calor já não é intenso e o frio começa a despontar como neblina, essas companhias e confissões parecem ganhar força.

Netuno, sempre solícito, gostou da ideia de gravar um vídeo cuja temática era: "o que eu já deixei de fazer por ser LGBTTI?". Netuno, sempre comunicativo, já havia acionado outras três pessoas que poderiam gravar também (antes mesmo de eu chegar à sua casa). Netuno, sempre animado, após a gravação nos convidou para um jogo de truco.

Truco, meio pau, nove, doze!

Truco, meio pau, nove, doze!

Truco, meio pau, nove, doze!

Entre aprender a jogar, escutar Tulipa Ruiz, comprar brigadeiro feito em casa e acariciar gatos, muitos afetos se movem, muitos saberes também. As discussões ficam acaloradas: nacional-desenvolvimentismo, expressões de gênero, nova esquerda do Brasil e do mundo, fluidez das sexualidades, "quando podemos marcar de beber algo?", "ih, começou a chover". Tudo é motivo pra entrar em mais uma rodada do jogo, pra adiar mais uma hora pra voltar pra casa, para não ir à Universidade.

O jogo de truco daquela tarde me transporta a outro, de semanas depois. Uma quarta-feira à noite, na mesa do bar barato no alto do morro da Cidade Alta com porção de batatas-fritas custando a bagatela de 9 reais: "se você sair daqui tendo gastado mais de 8 reais é porque você deu mole!". A caminhada com Netuno até chegar ali foi lenta. Propositalmente lenta. Términos de namoro, amadurecimento de relações, casamentos de uma semana e "agora vou assumir meu nome social!" fizeram com que os passos diminuíssem, que as lágrimas rolassem e que a respiração ficasse mais rápida.

No bar: muitos afetos e saberes - caminham juntos (lembrando de novo a mão direita e a mão esquerda de Pessoa). Muitos planos, muitos sonhos. Pessoas chegam a todo momento na mesa. O jogo de truco recomeça - Netuno havia trazido o carteado.

Truco, meio pau, nove, doze!

Truco, meio pau, nove, doze!

Truco, meio pau, nove, doze!

O jogo de "eu nunca" e "eu já" também aparece. As experiências menos puritanas chegam à mesa entre risadas, cachaças e "vamos fazer uma festa num motel?". Netuno estava sendo apresentado a todo mundo 
como masculino: sua primeira vez assim. As confissões aumentaram de ambas as partes. O frio também. "Pode ficar com meu casaco, Netuno! Está chovendo, mas isso pra mim não é nada não!” No final, a conta ficou em 15 reais pra mim (será que dei mole? Não importa!).

O caminhar de volta à casa é mais apressado: de volta ao conjunto de quitinetes que tinha me mostrado a dimensão do espaço. "Você passou por isso só por minha causa? A gente podia ter ido a outro lugar" - foi o que Netuno perguntou. "Não". Foi exatamente o que precisava. Despedidas feitas de promessas de reencontros que sumiriam feito neblina.

No caminhar à minha casa, a lembrança: "você está apaixonado e isso não é um elogio, é uma repreensão". Mas, pelo que me ensinou Netuno, apaixonar-se não pode ser isso, é cuidado! É recolher os cacos de vidro e colocar em uma lata com o bilhete "Cuidado, VIDRO", é pagar um pouco a mais, é emprestar o casaco e caminhar do lado.

(N. - 2018)

"O encontro com o despropósito" foi uma das cinco crônicas que compuseram a escrita do processo metodológico da pesquisa de mestrado. Essa diz de um dos encontros não-programados com Netuno. Uma narrativa de uma noite que misturou narrativas de tantas outras juventudes: juventude que bebe cerveja, juventude que tem desilusões amorosas, que sobe e desce ladeiras, que joga truco, que inventa, que cria nome, que produz gênero, que quer fazer uma festa de aniversário em um motel... Uma narrativa que visibiliza uma pluralidade que é constitutiva das juventudes.

Netuno foi o único nome escolhido no contexto da pesquisa. Assim que foi dada a oportunidade de escolha de algum nome diferente ao de registro, a pessoa escolheu um referente a um amigo de infância. Disse: "É um nome que eu gosto bastante assim. Eu acho que combina comigo". Alguns meses depois, no entanto, ela começou a utilizar esse nome escolhido para a pesquisa como um nome social (registrado, inclusive, nas pautas e documentos da universidade). A última mensagem que enviada para Netuno foi, justamente, para a escolha de algo novo - para que mantivéssemos seu anonimato (e talvez a assinatura do outro termo de compromisso). Mas, a resposta nunca chegou. Um dia após o envio, recebemos a notícia de seu suicídio. Com essa preocupação de manter seus nomes (de registro e social) ocultos, pensando na sua própria preocupação, sinalizada uma vez durante um segundo encontro, de preservar o anonimato de terceiros e, ainda, em algo que estivesse relacionado à sua história e ao seu corpo, optamos por nomear como Netuno. 
Nomes sendo inventados e também novas formas de lidar com a pesquisa, de lidar com o suicídio das identidades LGBT, de lidar com as juventudes. $\mathrm{O}$ que as juventudes trazem a todas as discussões que vimos propondo e que ainda desejamos propor?

Juventudes. Espaços-tempos-sujeitos que escapam do binário previsto de criança/adulto, quem aprende/quem ensina. Os sujeitos das juventudes são construídos social, política e culturalmente como a transição. Imersos em narrativas de que ainda estão no percurso que os levarão a ser sujeitos plenos (sujeitos da adultez). São-lhes concedidos direitos civis parciais. É recente a preocupação de diversas instituições sociais com as identidades das juventudes. Para a família ocidental (até poucas décadas) a criança passava a adulta por transformações corporais que indicavam já ter o direito (dever) do casamento. Para a igreja, um ritual marcava essa passagem, representada pela virada de uma fé que necessitava de orientação, para uma fé madura (escolhida e confirmada). Ou se era criança ainda, ou se era adulto; fazendo com que toda a lógica das instituições e artefatos culturais também construíssem esse binário. Em outras palavras, sua categorização atual como um não-binário da infância/adultez foi-se realizando ao longo do curso histórico dessas instituições. Para Cristiano Bedin da Costa,

\begin{abstract}
Do jovem, invariavelmente, diz-se: ele é aquele para quem o mundo está alhures. Ao meio do caminho entre o livre ser infantil e a exigências da vida adulta, o hoje no qual se instalam as juventudes parece ter a dupla materialidade de um papel rascunho, mas também descarte. (COSTA, 2013, p. 396, grifos do autor).
\end{abstract}

Nesse sentido, a juventude pode causar inquietação e desestabilizar a oposição binária em questão. É importante sinalizar que não tomamos as juventudes como trânsitos, como um simples trajeto de um sujeito "nãoformado". Argumentamos pelo meio do caminho, a partir da perspectiva de Derrida (2001) de nem/nem, nem isso/nem aquilo, da diferença. Também não romantizamos as juventudes empregando-lhes ares que invariavelmente seriam revolucionários.

Corroboramos as ideias de Ana Paula Corti (2004), Bill Green e Chris Bigum (2003) quando constroem um diálogo entre as juventudes e o cenário pós-moderno: são elas que vão experienciá-lo, produzindo suas relações, seus saberes, suas linguagens. Juventudes que, em seu meio do caminho, fazem saltar as experiências, tornando-as possibilidades de escolhas. Possibilidades de escolher um nome, de vocalizar novos incômodos, de rever prioridades. 
Desestabilizam também pela pluralidade: se a idade pode, por vezes, as unir enquanto categoria, são as experiências que vivenciam que vão, principalmente, as reunir em torno do bar, para retomar a crônica de Netuno. Quantas são as pessoas, quantas são as experiências.

Identidades que foram se construindo desde a infância vão se diferenciando, pluralizando pela socialização. Alberto Melucci (1997, p. 12-13) vai apontar que o movimento juvenil (e aqui entendemos movimento como as ações de socialização que as juventudes irão pensar para si: desde uma festa no motel até uma ocupação política de um espaço público) se constituirá por uma rede de diferentes identidades que testarão experiências e pontos de vista. Como analisa o mesmo autor, as ações realizadas pelas juventudes sinalizam para a solução de "um problema relacionado não somente com as suas próprias condições de vida, mas também com os meios de produção e distribuição de recursos de significado" (MELUCCI, 1997, p. 13). Nesse sentido, as juventudes e suas consequentes ações ora poderão desafiar algumas lógicas binárias estabelecidas, ora poderão reforçá-las.

\section{CONSIDERAÇÕES FINAIS}

Nesse texto procuramos apresentar algumas problematizações sobre dimensões de gênero, identidades e juventudes, a partir das narrativas de jovens que elaboram experiências de negociação com a não-binaridade de gênero. A criação e debruçar sobre esse enlace têm permeado nossas pesquisas e trabalhos com jovens, conduzindo a caminhos instigantes e desafiadores, tendo que construir metodologias na instabilidade, no movimento e na fluidez dessas categorias. Ainda há muito que explorar e ampliar nos questionamentos levantados por aqui, a discussão não se encerra, mas continua em rizoma. Para a última sessão deste texto, no entanto, sinalizamos apenas para dois apontamentos: a questão da utilização de narrativas como metodologia de trabalho e a questão do próprio enlace em si.

A produção de narrativas em contextos de pesquisas, incluindo aquelas com as quais estamos envolvidos, expõe uma série de narrativas com jovens para dizer de suas histórias de vida, histórias de morte, histórias de desconforto, histórias de encantamento etc. Essa escolha teórico-metodológica tem nos proporcionado maior aproximação e aprofundamento das temáticas que exploramos, além de - como intentamos fazer nessa escrita - nos lançar a novas imaginações que não fiquem apenas na análise do texto narrativo, mas que 
extrapole na utilização dos conceitos produzidos na fala como epistemologias, lentes pra análises de outras situações. Acerca desse aspecto, Cecília Galvão nos diz que

a narrativa, como metodologia de investigação, implica uma negociação de poder e representa, de algum modo, uma intrusão pessoal na vida de outra pessoa. Não se trata de uma batalha pessoal, mas é um processo ontológico, porque nós somos, pelo menos parcialmente, constituídos pelas histórias que contamos aos outros e a nós mesmos acerca das experiências que vamos tendo. (GALVÂO, 2005, p. 330).

Nesse sentido, acreditamos que Elfo, Irene, Netuno, nós e quem nos lê se inscreve nessa teia de subjetivação, acrescentando outras epistemologias e modificando as existentes. $\mathrm{O}$ trabalho com gêneros, identidades e juventudes em Educação tem nos modificado o ser e o fazer principalmente a partir do que ouvimos e narramos nos textos.

Por fim, quanto ao esse enlace aqui exposto, argumentamos que qualquer tentativa de fixação nos binários pode ser desfeita pela pulsação da subjetividade. Em outras palavras, o movimento político e subjetivo do gêneroidentidade-juventude parece possibilitar aos sujeitos se desprender das binaridades, oposições e estigmas e constituir outras possibilidades de existência. Nesse sentido, vemos a movimentação desse enlace como uma usina que produz incessantemente sensibilidades, pensamentos, emoções, desejos, modos de ser, posturas políticas, relações de interação social, entre outros.

Acompanhando Gilles Deleuze e Félix Guattari quando indicam que "não se pode contar com um dualismo ou uma dicotomia, nem mesmo sob a forma rudimentar do bom e do mau” (DELEUZE e GUATTARI, 1995, p. 17), enlaçamos essas dimensões enquanto experiências atravessadas, enquanto ferramentas que podem ser utilizadas tanto para construir uma narrativa quanto para lançar olhar ao mundo. Gêneros que ajudam produzir conhecimento; identidades que ajudam a deslocar a fixidez e perceber os processos como complexidades; juventudes que ajudam a perceber intensidades, tempos e espaços, mudanças. Mas também gêneros para produzir deslocamentos; identidades para entender os espaçamentos; juventudes para construir saberes. 
Continuando com gêneros para tensionar os intensos; identidades para teorizar; juventudes para fazer vibrar e desmoronar a palavra amor. E ainda tantas outras configurações possíveis que se abrem.

\section{REFERÊNCIAS}

BENTO, Berenice. Nome social para pessoas trans: cidadania precária e gambiarra legal. Contemporânea - Revista de Sociologia da UFSCar, São Carlos, v. 4, n. 1, jan.-jun. p. 165-182. 2014

BUTLER, Judith. Problemas de gênero: feminismo e subversão da identidade. 236p. Rio de Janeiro: Editora Record, 2003.

BUTLER, Judith. Regulações de Gênero. Cadernos Pagu. Campinas, n. 42. p. 249-274. 2014.

CÉSAR, Maria Rita de Assis. A crítica da identidade nos movimentos feminista, lgbt: Michel Foucault e as ressonâncias na educação. Teoria e Prática da Educação, v. 17, n. 2, p. 97-104, 2014.

CORTI, Ana Paula. Diálogos com o mundo juvenil: subsídios para educadores. São Paulo: Ação Educativa, 2004.

COSTA, Cristiano Bedin da. "HOJE SEU AMOR, AMANHÃ O MUNDO": discursos tímidos sobre jovens pesquisadores. Linguagens, Educação e Sociedade. Dossiê Educação e Juventudes - Teresina: EDUFPI. p. 393-412, 2013

DAYRELL, Juarez; GOMES, Nilma Lino. Juventude, práticas culturais e identidades negras. Relatório de Pesquisa. 2004. Mimeo.

DAYRELL, Juarez. Ser alguém na vida: juventude, escola e a busca por reconhecimento. Belo Horzonte: UFMG, 2014.

D'ÁVILA REIS, Cristina. O uso da metodologia queer em pesquisa no campo do currículo. In: MEYER, Dagmar Estermann; PARAÍSO, Marlucy Alves (Organizadoras). Metodologias de pesquisas pós-críticas em educação. Belo Horizonte, Mazza Edições, 2012, p. 243-260. 
DELEUZE, Gilles; GUATTARI, Fêlix. Mil platôs - capitalismo e esquizofrenia, vol. 1/Tradução de Aurélio Guerra Neto e Célia Pinto Costa. Rio de janeiro: Ed, v. 34, p. 94, 1995.

DERRIDA, Jacques. Posições. Trad. Tomaz Tadeu da Silva. Belo Horizonte, MG: Autêntica, 2001.

FOUCAULT, Michel. Ditos e Escritos I: Problematização do sujeito: psicologia, psiquiatria e psicanálise. 2. ed. Rio de Janeiro: Forense Universitária, 2002.

FOUCAULT, Michel. Microfísica do poder. 20. ed. São Paulo: Graal, 2004.

GALVÃO, Cecília. Narrativas em Educação. Ciência \& Educação (Bauru), v. 11, n. 2, p. 327-345, 2005.

GREEN, Bill; BIGUM, Chris. Alienígenas na sala de aula. In: SILVA, Tomaz Tadeu da. (Org.). Alienígenas na sala de aula: uma introdução aos estudos culturais em educação. 5. ed. Petrópolis: Vozes, p. 208-43, 2003.

GUIMARÃES, Leonardo; ROSA, Alison; JUNIOR, Amarante; RAYTHZ, Letícia; SCHMIDT, Ana Paula; de Deus, Gian; REIS, Jéssica; ROCHA, Mariana; e GOMES, Paula. Transexualismo: uma análise psicológica na inserção social. Perspectiva: ciência e saúde, v. 1, n. 1, 2016.

HALL, Stuart. Identidades culturais na pós-modernidade. Trad. Tomaz Tadeu da Silva, Guacira Lopes Louro. Rio de Janeiro: DP\&A, 2011.

HERMANN, Nadja. A questão do outro e o diálogo. Revista Brasileira de Educação. São Paulo, v. 19, n. 57, p. 477-493, 2014.

MELUCCI, Alberto. Juventude, tempo e movimentos sociais. Revista Brasileira de Educação. São Paulo v. 5, n. 6, p. 5-14, 1997.

MUYLAERT, Camila Junqueira; Sarubbi Jr, Vicente; Gallo, Paulo Rogério; Neto, Modesto Leite Roli; e Reis, Alberto Olavo. Entrevistas narrativas: um importante recurso em pesquisa qualitativa. Revista da Escola de Enfermagem da USP, v. 48, n. spe2, p. 184-189, 2014.

SCHWACH, Karen. A mudança de nome em indivíduos transgêneros em pauta na Conferência Internacional de Aids. Agência de Notícias da AIDS, São Paulo. 2012. 
SEGATO, Rita. Gênero e colonialidade: em busca de chaves de leitura e de um vocabulário estratégico descolonial. e-cadernos ces, n. 18, 2012.

SQUIRE, Corinne. O que é narrativa? Civitas - Revista de Ciências Sociais, vol. 14, núm. 2, p. 272-284. 2014.

WOODWARD, Kathryn. Identidade e diferença: uma introdução teórica e conceitual. IN: SILVA, Tomaz Tadeu da. Identidade e diferença: a perspectiva dos estudos culturais. Petrópolis: Vozes, 2000, p. 7-72.

Recebido em: 15/02/2019

Aprovado em: 17/06/2019 